\title{
Identification of a Somatodendritic Targeting Signal in the Cytoplasmic Domain of the Transferrin Receptor
}

\author{
Anne E. West, ${ }^{1}$ Rachael L. Neve, ${ }^{2}$ and Kathleen M. Buckley ${ }^{1}$ \\ ${ }^{1}$ Department of Neurobiology, Harvard Medical School, Boston, Massachusetts 02115, and 2Department of Genetics, \\ Harvard Medical School, McLean Hospital, Belmont, Massachusetts 02178
}

\begin{abstract}
Neurons are highly polarized cells that must sort proteins synthesized in the cell body for transport into the axon or the dendrites. Given the amount of time and energy needed to deliver proteins to the distal processes, neurons must have high fidelity mechanisms that ensure proper polarized protein trafficking. Although a variety of proteins are localized either to the somatodendritic domain or to the axon (Craig and Banker, 1994), the question of whether there are signal-dependent mechanisms that sort proteins to distinct neuronal domains is only beginning to be addressed. To determine sequence requirements for the polarized sorting of transmembrane proteins into dendrites, we expressed mutant transferrin receptors in cultured rat hippocampal neurons, using a defective herpes
\end{abstract}

virus vector. Wild-type human transferrin receptor colocalized with the endogenous protein in dendritic endosomes and was strictly excluded from axons, despite overexpression. Polarized targeting was abolished by deletion of cytoplasmic amino acids $7-10,11-14$, or 19-28, but not 29-42 or 43-58. These deletions also increased the appearance of transferrin receptor on the plasma membrane, implying that endocytosis and dendritic targeting are mediated by overlapping signals and similar molecular mechanisms. In addition, we have characterized a specialized para-Golgi endosome poised to play a critical role in the polarized recycling of transmembrane proteins.

Key words: neuronal polarity; dendrites; transferrin receptor; protein sorting; endocytosis; endosomes
The transferrin receptor ( $\mathrm{TfR}$ ) is a recycling transmembrane protein localized to dendrites in neurons; it is strictly excluded from the axon (Cameron et al., 1991; Parton et al., 1992). The TfR is endocytosed constitutively from the plasma membrane via clathrin-coated pits (Goldstein et al., 1985). Rapid internalization of the receptor is mediated by binding of the clathrin-associated protein AP2 to the TfR endocytosis motif, which is critically dependent on the tyrosine at amino acid 20 in the cytoplasmic domain (Jing et al., 1990; Ohno et al., 1995). In fibroblasts after initial internalization to an acidic sorting endosome (DautryVersat et al., 1983), the TfR passes through a distinct para-Golgi compartment, the recycling endosome, before returning to the plasma membrane (Yamashiro et al., 1984; Mayor et al., 1993; Gruenberg and Maxfield, 1995).

In many epithelial cell lines, polarized sorting of the TfR to the basolateral surface occurs both with the exit of newly synthesized protein from the trans-Golgi network (TGN) and with passage of the TfR through the endocytic pathway (Fuller and Simons, 1986; Matter et al., 1993; Odorizzi et al., 1996). Although short cytoplasmic sequence motifs have been implicated in the basolateral targeting of a number of transmembrane proteins in polarized

Received March 14, 1997; revised May 19, 1997; accepted May 29, 1997.

This work was supported by National Institutes of Health Grant NS27536 (K.M.B.), the Stuart H. Q. and Victoria Quan Fellowship in Neurobiology, and National Research Scientist Award 2 T32 NS07009-21 (A.E.W.). We thank Cheryl Sadow and Dan Lindberg for technical assistance, Dr. Ian Trowbridge for antibody H68.4, Dr. Richard Vallee for polyclonal antibodies to MAP2, Dr. Philip Leopold for Cy3-conjugated transferrin, Dr. Fred Maxfield for DiI-conjugated LDL, and Dr. Morris Birnbaum for the human transferrin receptor cDNA. We also thank Philip Leopold, Tim McGraw, Fred Maxfield, David Caplan, and Karl Matlin for invaluable advice and suggestions and Jeffrey Boone Miller, Chet Provoda, and Patty Purcell for comments on this manuscript.

Correspondence should be addressed to Dr. Kathleen M. Buckley, Department of Neurobiology, Harvard Medical School, Goldenson Building, Room 510, 220 Longwood Avenue, Boston, MA 02115.

Copyright (C) 1997 Society for Neuroscience $\quad 0270-6474 / 97 / 176038-\bullet 05.00 / 0$ epithelial cells (Matter and Mellman, 1994), the sequences that mediate polarized sorting of the TfR remain unknown (Dargemont et al., 1993). Recognition of these sequences and polarized recycling in epithelial cells occurs from a specialized endosomal system that extends into both the apical and basolateral cytoplasm and shares transmembrane proteins endocytosed from both domains (Apodaca et al., 1994; Knight et al., 1995; Odorizzi et al., 1996).

In neurons the precise identities of sorting signals responsible for targeting endogenous membrane proteins to either the axonal or somatodendritic domain and the compartments in which sorting occurs are unknown in large part because of the technical difficulties of expressing mutated proteins in neurons. However, recent advances in neuronal gene transfer by viral infection have made it possible to express recombinant constructs in neurons with high efficiency and low toxicity (Ho, 1994; Olkkonen et al., 1994). We have used a defective herpes simplex virus (HSV-1) vector expression system (Spaete and Frenkel, 1982; Geller and Breakefield, 1988) to deliver a panel of human transferrin receptor (hTfR) deletion constructs to cultured hippocampal neurons for localization. In this paper we demonstrate that a signal in the hTfR cytoplasmic domain from amino acids 7-14 and 19-28 directs the dendritic localization of the protein. Deletions that reduced preferential dendritic targeting also increased plasma membrane staining for hTfR, indicating that endocytosis and dendritic targeting are controlled by overlapping signals and potentially similar mechanisms in these cells. We also have characterized a para-Golgi recycling endosome in neurons with many characteristics of the endosomal compartments that have been shown in other cell types to be capable of sorting recycling membrane proteins. Together, these data provide the first evidence for the signals and pathways that mediate polarized sorting of a somatodendritic protein in neurons. 


\section{MATERIALS AND METHODS}

Antibodies. Primary antibodies used in this study were as follows: monoclonal antibody (mAb) against hTfR (H68.4) was kindly provided by Dr. Ian Trowbridge (The Salk Institute, La Jolla, CA) or purchased from Zymed (San Francisco, CA); the cell line for mAb against hTfR (OKT9) was purchased from American Type Culture Collection (Rockville, MD); polyclonal Ab against MAP2 was kindly provided by Dr. Richard Vallee (Worchester Foundation for Experimental Biology, Shrewsbury, MA).

Hippocampal cell culture. For fluorescence microscopy, primary cultures of rat hippocampal neurons were prepared from embryonic day 18 (E18) rats (Sprague Dawley, Taconic Farms, NY), as described (Banker and Cowan, 1977; Goslin and Banker, 1991). Dissociated neurons were plated onto coverslips at a density of 2600 cells $/ \mathrm{cm}^{2}$ and cocultured over glia. Neurons on coverslips were grown for 5-9 d [stage 4-5 cells; (Dotti et al., 1988)] before infection or fixation. For Western analysis, dissociated cortical neurons from E18 rats were plated at 53,000 cells $/ \mathrm{cm}^{2}$ onto poly-L-lysine-coated $60 \mathrm{~mm}$ tissue culture dishes and fed with medium that had been conditioned over glia for $24 \mathrm{hr}$. Cortical neurons were cultured for $14 \mathrm{~d}$ before infection and homogenization.

DNA constructs. An hTfR cDNA (McClelland et al., 1984) was kindly provided by Dr. Morris Birnbaum (University of Pennsylvania, Philadelphia, PA). A 5' BglII site was generated by PCR immediately upstream of the start codon. All PCR was done with the enzyme Pfu (Stratagene, La Jolla, CA). On the $3^{\prime}$ end an $X b a$ I site 45 bases past the stop codon was used. The construct was subcloned into pBluescript $\mathrm{SK}^{-}$(Stratagene) between the Bam HI and $X b a \mathrm{I}$ sites and then excised with $\mathrm{SalI}$ and $\mathrm{XbaI}$ for cloning into the defective herpes amplicon vector pHSVPrPUC (Geller et al., 1993). Deletion mutants of hTfR were constructed in Bluescript SK ${ }^{-}$by the technique of PCR-ligation-PCR (Ali and Steinkasserer, 1995). Briefly, blunt-ended products were generated in an initial reaction flanking the region to be deleted. The products were ligated, and a second PCR reaction that used the outside primers created a single final product across the ligation. After PCR the region from $N d e I$ (at 451 bases past the translation start site) to $X b a I$ was replaced with hTfR cDNA that had not undergone PCR to eliminate potential mutations. PCR products were sequenced fully from the start site to the NdeI site to ensure that no unwanted mutations had been introduced during PCR.

Herpes virus amplicon packaging. Engineered constructs were packaged as defective HSV-1 particles, using an amplicon-based vector as described (Geller and Breakefield, 1988; Lim et al., 1996). Briefly, cDNAs in the vector pHSVPrPUC were transfected into 2-2 cells (Smith et al., 1992) with Lipofectamine (Life Technologies, Gaithersburg, MD) and superinfected $1 \mathrm{~d}$ later with the helper virus strain $5 \mathrm{dl} 1.2$ (McCarthy et al., 1989). Virus was harvested and passaged on fresh 2-2 cells three additional times to amplify the yield and to increase the ratio of vector to helper virus. Stocks were stored in small aliquots at $-70^{\circ} \mathrm{C}$ and thawed a maximum of three times. Helper virus was titered in a plaque assay on 2-2 cells, and the vector-containing particles were titered by expression in PC12 cells. The titers for each stock of virus used in this study are listed here in units of infectious particles $\times 10^{6} / \mathrm{ml}$ as vector $(\mathrm{v})$, helper $(\mathrm{h})$, and vector-to-helper ratio (v:h): hTfR, 56 (v), 520 (h), 0.1 (v:h); d3-59/TfR, 31 (v), 107 (h), 0.3 (v:h); d3-18/TfR, 27 (v), 100 (h), 0.3 (v:h); d19-28/TfR, 120 (v), 240 (h), 0.5 (v:h); d29-42/TfR, 162 (v), 550 (h), 0.3 (v:h); d43-58/TfR, 213 (v), 320 (h), 0.7 (v:h); d3-6/TfR, 165 (v), 360 (h), 0.5 (v:h); d7-10/TfR, $287(\mathrm{v}), 310$ (h), 0.9 (v:h); d11-14/TfR, 162 (v), 340 (h), 0.5 (v:h); and d15-18/TfR, 172 (v), 580 (h), 0.3 (v:h).

Infection of neurons. Coverslips were removed from the glial cocultures and placed cell-side-up in $1 \mathrm{ml}$ of neuronal N2 medium (Goslin and Banker, 1991). Virus was added to the medium at a multiplicity of infection of 1 (based on the vector titer). Cells were incubated for $20 \mathrm{hr}$ before being fixed and stained for expression. Cortical cultures for Western analysis were infected by adding $3 \mathrm{ml}$ of fresh N2 medium plus virus at a multiplicity of infection of 0.35 to the culture. The cells were incubated for $24 \mathrm{hr}$ before homogenization.

Immunofluorescence. Cells were fixed in $4 \%$ paraformaldehyde and $0.05 \%$ glutaraldehyde in PBS for $10 \mathrm{~min}$ at $37^{\circ} \mathrm{C}$. Then the cells were blocked and permeabilized in a solution of $16 \%$ goat serum and $0.1 \%$ Triton X-100 in PBS, $\mathrm{pH} \mathrm{7.4,} \mathrm{for} 1 \mathrm{hr}$ at room temperature. Primary antibodies were applied in the blocking/permeabilizing solution at $4^{\circ} \mathrm{C}$ overnight. After the cells were washed twice with PBS containing $0.05 \%$ Triton X-100 (to minimize shear force on the neurons), goat anti-mouse IgG conjugated to fluorescein (Pierce, Rockford, IL) and goat anti-rabbit IgG conjugated to Texas Red (Vector Laboratories, Burlingame, CA) secondary antibodies were bound for $60 \mathrm{~min}$ at room temperature in the blocking/permeabilizing solution. Cells were mounted in Vectashield mounting medium (Vector Laboratories) to resist bleaching. Neurons were viewed at $40 \times($ dry) or $63 \times$ (oil) on a Zeiss Axioskop (Oberkochen, Germany) equipped with epifluorescence and photographed on Kodak ASA 400 black and white print film or color slide film (Rochester, NY). All photographs were taken with $30 \mathrm{sec}$ exposures and treated equivalently during developing. Slides or negatives were scanned into Adobe Photoshop for display. All backgrounds were adjusted equally to ensure that the images of different constructs could be compared legitimately.

Homogenization of cortical cultures for Western analysis. Neurons from one $60 \mathrm{~mm}$ dish $\left(\sim 1.5 \times 10^{6}\right.$ cells $)$ were washed with $3 \mathrm{ml}$ of buffer A [containing (in $\mathrm{mM}$ ): $150 \mathrm{NaCl}, 10 \mathrm{HEPES}, \mathrm{pH} 7.4,1$ EGTA, and 1 $\mathrm{MgCl}_{2}$ ], scraped into $1 \mathrm{ml}$ of buffer $\mathrm{A}$, and spun down for $5 \mathrm{~min}$ at $5500 \times$ g. Cells were resuspended in $0.45 \mathrm{ml}$ of cold $\mathrm{ddH}_{2} \mathrm{O}$ and homogenized in a $1 \mathrm{ml}$ Teflon-glass tissue homogenizer for 10 strokes at $500 \mathrm{rpm}$. After homogenization the osmolarity of the solution was adjusted with $50 \mu \mathrm{l}$ of $10 \times$ buffer A. Nuclei and unbroken cells were spun out at $1000 \times g$ for $5 \mathrm{~min}$, and a protease inhibitor cocktail was added to the supernatant (1 $\mu \mathrm{g} / \mathrm{ml}$ pepstatin, $1 \mu \mathrm{g} / \mathrm{ml}$ aprotinin, $1 \mathrm{~mm}$ PMSF, and $1 \mu \mathrm{g} / \mathrm{ml}$ leupeptin). A $10 \mu \mathrm{l}$ sample of the homogenate was solubilized in $0.1 \%$ SDS and assayed for protein concentration with a BCA protein assay (Pierce). To pellet membranes from the homogenate, we mixed the $0.5 \mathrm{ml}$ with $2.5 \mathrm{ml}$ of buffer $\mathrm{A}$ and placed it in $3 \mathrm{ml}$ polycarbonate ultracentrifuge tubes (Beckman, Fullerton, CA). Membranes were pelleted at $150,000 \times g$ for $2 \mathrm{hr}$ at $4^{\circ} \mathrm{C}$ in a tabletop TLA100.4 rotor. Membrane pellets were resuspended directly into SDS sample buffer, and equal protein for each construct was loaded in serial dilutions onto SDS-PAGE gels.

Western blotting. Samples were separated on 10\% SDS-PAGE minigels and then transferred overnight at $50 \mathrm{~V}$ to nitrocellulose in transfer buffer (20 mM Tris, $150 \mathrm{~mm}$ glycine, and $20 \%$ methanol). Proteins were visualized with Ponceau $\mathrm{S}$ to determine the fidelity of transfer. Blots were incubated for $1-8 \mathrm{hr}$ at room temperature in a solution of $5 \% \mathrm{milk} / 5 \%$ goat serum in TBST ( $50 \mathrm{~mm}$ Tris, $150 \mathrm{~mm} \mathrm{NaCl}$, and $0.05 \%$ Tween 20 ) to block nonspecific binding sites. Primary antibodies were applied overnight at $4^{\circ} \mathrm{C}$ in the blocking solution. Goat anti-mouse IgG conjugated to HRP (Pierce) was bound at a dilution of 1:5000 in blocking solution for $60 \mathrm{~min}$ at room temperature. Blots were reacted for $5 \mathrm{~min}$ with Pierce "SuperSignal" ECL reagents diluted 1:5 in $\mathrm{ddH}_{2} \mathrm{O}$ and exposed to Kodak $\mathrm{X}-\mathrm{AR}$ film. Bands were quantitated on a densitometer (LKB-Wallac, Gaithersburg, MD), with the linear range of the film determined by comparison to synaptosomal standards.

Transferrin, low-density lipoprotein (LDL), and C6-NBD-ceramide uptake. Coverslips were placed face up in 12-well dishes in room air on a $37^{\circ} \mathrm{C}$ slide warmer. Cells were washed twice with HEPES-buffered solution containing (in $\mathrm{mM}$ ): $119 \mathrm{NaCl}, 2.5 \mathrm{KCl}, 2 \mathrm{CaCl}_{2}, 2 \mathrm{MgCl}_{2}, 25$ HEPES, pH 7.4, and 30 glucose with $0.1 \%$ albumin. The TGN was labeled by incubating 8-13 $\mathrm{d}$ in vitro (DIV) neurons in $5 \mu \mathrm{M}$ C6-NBDceramide (Molecular Probes, Eugene, OR) for $10 \mathrm{~min}$ at $37^{\circ} \mathrm{C}$. The C6-NBD-ceramide was bound to $0.34 \mathrm{mg} / \mathrm{ml}$ BSA (essentially fatty acid-free; Sigma, St. Louis, MO) in HEPES-buffered solution. C6-NBDceramide was back-extracted from the cells with three $10 \mathrm{~min}$ washes of $3.4 \mathrm{mg} / \mathrm{ml}$ BSA in HEPES-buffered solution. Cy3-conjugated transferrin (Tf; kindly provided by Dr. Philip Leopold, Cornell University Medical School, New York, NY) was added to the first two washes (20 min total) at $25 \mu \mathrm{g} / \mathrm{ml}$ and then removed in the final $10 \mathrm{~min}$ wash. Cells were washed twice in ice-cold HEPES-buffered solution before being fixed. Receptor-mediated uptake was assessed by blocking the binding of the labeled Tf with a 10-fold molar excess of unlabeled Tf. Fluoresceinconjugated Tf (Molecular Probes) was added to the medium of 8-13 DIV neurons for $60 \mathrm{~min}$ at $100 \mu \mathrm{g} / \mathrm{ml}$ in HEPES-buffered solution. The Tf was washed out for $10 \mathrm{~min}$ in HEPES-buffered solution, and then DiI-conjugated LDL (kindly provided by Dr. Fred Maxfield, Columbia University, New York, NY) was added to the neurons for $5 \mathrm{~min}$ at 10 $\mu \mathrm{g} / \mathrm{ml}$. Cells were washed twice in ice-cold HEPES buffer before fixing. Cells were viewed at $63 \times$, and some images were captured with a chilled CCD camera and then transferred to Adobe Photoshop for display.

\section{RESULTS}

\section{A dendritic targeting signal is found in the cytoplasmic domain of the transferrin receptor}

The axons and dendrites of neurons can be distinguished both by their characteristic morphology in culture and by the polarized segregation of molecular markers to these compartments (Goslin and Banker, 1991). We have chosen to work with low-density 

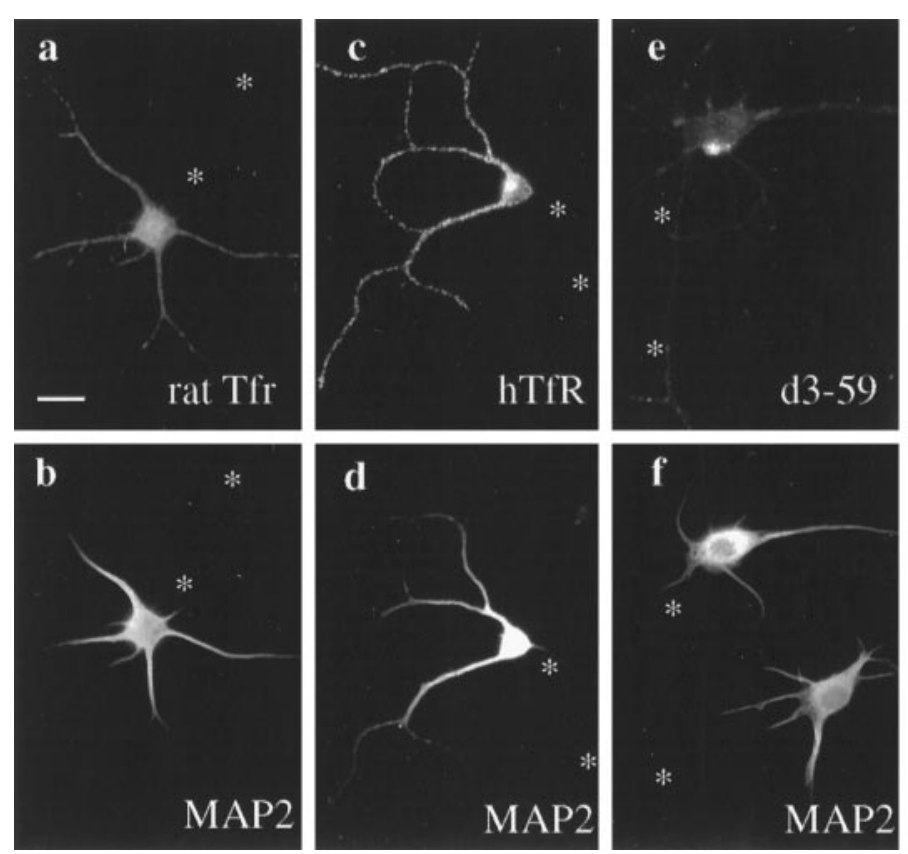

cultures of hippocampal neurons from E18 rat, which undergo a characteristic development of polarity. By 5-7 DIV the neurons are at stage 4 of development (Dotti et al., 1988). At this stage each cell has elaborated a single long, thin axon that is of uniform caliber along its length, branches extensively distal from the cell body, and that contains concentrations of synaptic vesicle proteins in the distal regions (Fletcher et al., 1991). Also emerging from each cell body are several thick dendrites that taper toward their distal ends, branch at acute angles, and are labeled by the microtubule-associated protein MAP2 (Caceres et al., 1984). TfR is confined to the dendrites at this stage, where it appears in intracellular puncta (Cameron et al., 1991) (Fig. 1a). Both MAP2 and the endogenous rat TfR are strictly excluded from the axon (Fig. 1a,b), so axons can be identified in immunofluorescence as processes lacking these markers (see asterisks in Fig. 1).

To uncover sequences that are responsible for the dendritic localization of the $\mathrm{TfR}$ in neurons, we expressed a series of deletion mutants of the hTfR in cultured hippocampal neurons. The hTfR is a type II integral membrane protein of 760 amino acids of which the N-terminal residues 1-61 are cytoplasmic (McClelland et al., 1984). The recombinant cDNAs were expressed from defective HSV-1 vectors packaged by a helper virus as HSV particles, which infect neurons with high efficiency and low toxicity (Geller and Breakefield, 1988; Geller et al., 1991; Ho, 1994). The wild-type hTfR, expressed in neurons from a defective HSV-1 vector, shows an identical distribution to the endogenous protein (Fig. 1c). Bright puncta of immunoreactivity are seen throughout the MAP2-positive dendrites of the infected cell but are not detectable in the MAP2-negative axon (asterisks). The human TfR is stained with the monoclonal antibody OKT9, which binds the extracellular domain of the protein (Sutherland et al., 1981) and does not cross-react with the endogenous rat TfR (Fig. 1g). These results demonstrate that overexpression of the hTfR alone is not sufficient to cause it to appear in the axon. In addition, the proper targeting of the hTfR expressed from a defective viral vector shows that viral infection itself does not alter cellular morphology or intracellular protein-targeting pathways.

Deletion of the hTfR cytoplasmic domain allows the mutant

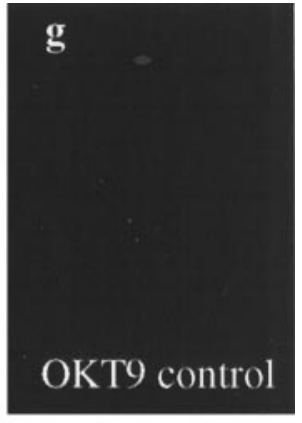

Figure 1. The distribution of endogenous and exogenous TfR in hippocampal neurons. Hippocampal neurons were cultured for 5-7 d before fixation ( $a, b$ and $g, h)$ or infection, followed $20 \mathrm{hr}$ later by fixation $(c-f) . b, d, f, h$, The dendritic marker MAP2. a, The endogenous rat TfR in a 7 DIV neuron. $c, h T f R$ expressed from an infected herpes virus vector. $e$, A deletion mutant of the $h T f R$ missing cytoplasmic amino acids $d 3-59$, expressed from a viral vector. $g$, An uninfected neuron stained with the antibody $O K T 9$ against $h T f R$. The endogenous rat TfR in $a$ was present in intracellular puncta restricted to MAP2-positive dendrites and excluded from axons (axons are MAP2-negative processes marked by asterisks). Full-length human TfR expressed by viral infection (c) also was restricted to the dendrites and found in intracellular puncta despite overexpression. Deletion of the cytoplasmic domain of $h T f R$ (e) redirected the expressed protein into the axon as well as the dendrites. The tailless mutant protein was found on the plasma membrane of both types of processes. The antibody OKT9 against $h T f R$ did not stain uninfected neurons $(g)$. Scale bar in $a, 20 \mu \mathrm{m}$. protein to enter the axon as well as the dendrites (Fig. 1e). A deletion mutant of hTfR was constructed by PCR that lacks amino acids 3-59 of the 61 amino acid cytoplasmic domain. Expression of this construct in neurons resulted in immunoreactivity for the hTfR that was primarily on the plasma membrane of both axons and dendrites (Fig. 1e). The plasma membrane distribution of this construct is consistent with the localization of a rapid internalization signal in the cytoplasmic domain of TfR that is critically dependent on tyrosine 20 (Jing et al., 1990). This result indicates that a signal mediating sorting of the hTfR to the dendrites of hippocampal neurons is found in the cytoplasmic domain.

\section{The dendritic targeting signal overlaps with the internalization motif}

To localize the dendritic targeting information more precisely in the hTfR, we divided the large deletion (amino acids 3-59) we had made in the cytoplasmic domain of hTfR into four smaller deletions: the $\mathrm{N}$ terminus (amino acids 3-18, notated here $\mathrm{d} 3-18$ ), the internalization region (d19-28), the central domain (d29-42), and the juxtamembrane domain (d43-58). Defective HSV-1 vectors were constructed for the hTfR with each of these smaller deletions. Figure 2 shows the expression patterns of these constructs as compared with the dendritic marker MAP2. Deleting either amino acids $3-18$ or amino acids $19-28$ caused hTfR to label the plasma membrane of both axons and dendrites in a pattern similar to that observed on deletion of 3-59 (Fig. $2 a-d$ ). Deleting amino acids 29-42 or 43-58 did not alter the pattern from that of the wild-type hTfR: these constructs were found in intracellular puncta in the dendrites only (Fig. $2 e-h$ ). Thus the dendritic targeting signal in hTfR is in the N-terminal 28 amino acids of the cytoplasmic domain, a region that also contains the internalization sequence for the hTfR. Deletions of this region that disrupt dendritic targeting also increase plasma membrane staining.

We showed in Figure 1 that mere overexpression of the hTfR was not sufficient to mistarget the protein. However, to be certain that the effects we were seeing on targeting in Figure 2 were attributable specifically to the deletions we had made and not 

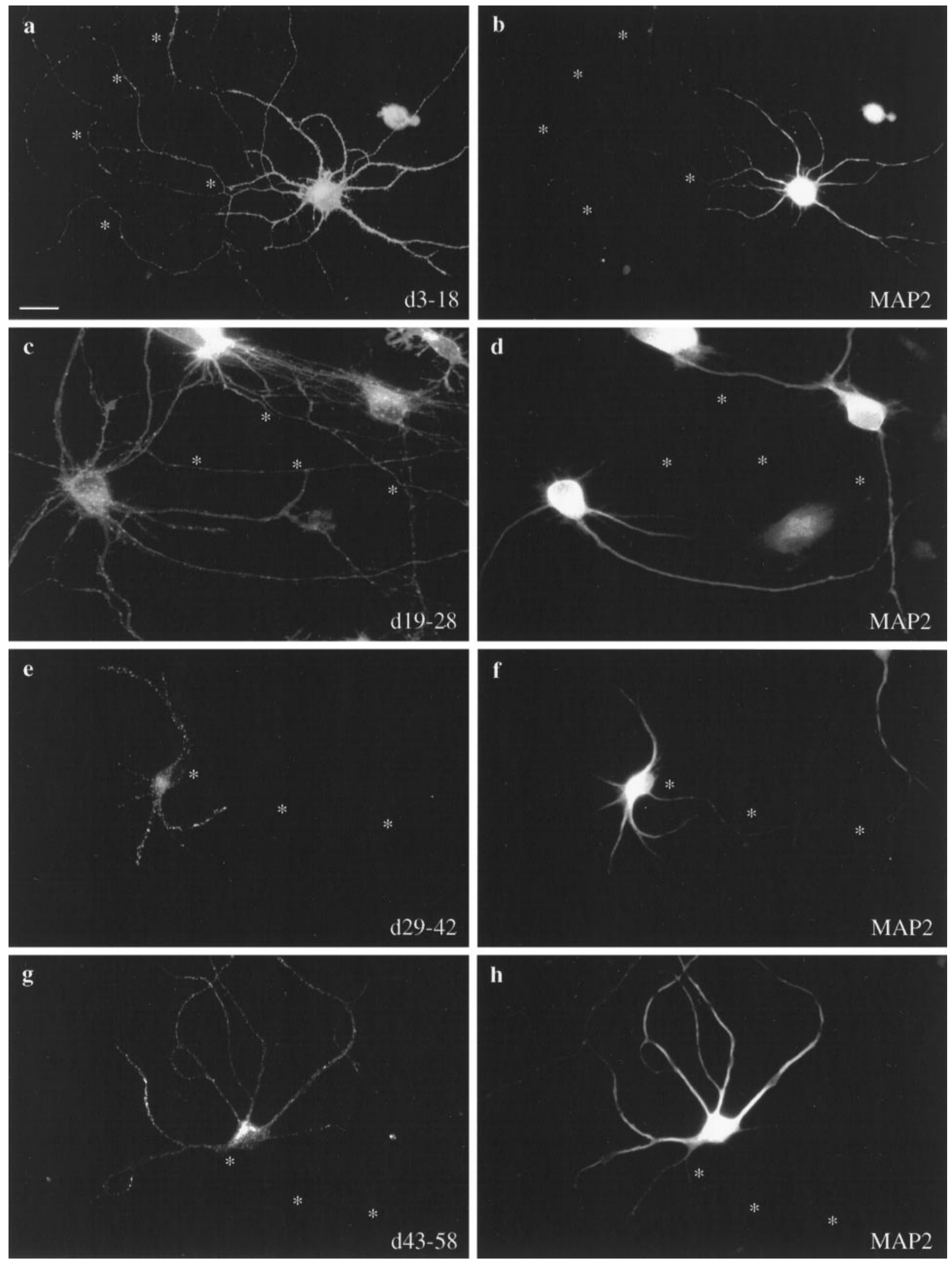

Figure 2. Localization of hTfR with deletions in the cytoplasmic domain. Deletions were constructed in the hTfR sequence by PCR. Deletion constructs were expressed from herpes virus vectors infected into 5-7 DIV neurons. The expressed protein was localized $20 \mathrm{hr}$ after infection and compared with the dendritic marker MAP2. Asterisks mark the location of axons. $a, c, e, g$, hTfR deletion mutants. $b, d, f, h, M A P 2$ immunoreactivity in the same neurons. $a$, $d 3-18 / \mathrm{hTfR} ; c, d 19-28 / \mathrm{hTfR} ; e, d 29-42 / \mathrm{hTfR} ; g, d 43-58 / \mathrm{hTfR}$. Deletions from amino acids $29-42$ or $43-58$ in hTfR did not alter the dendritic localization of the constructs $(e-h)$. These constructs were internalized efficiently, as indicated by the punctate intracellular pattern of the immunofluorescence. Deletion of either amino acids 3-18 or 19-28 disturbed dendritic targeting, because these constructs were seen in MAP2-negative axons (asterisks in $a$ and $c$ ), and disturbed steady-state distribution, because the staining labeled the plasma membrane (see especially dendrites in $a$ ). Plasma membrane staining of filopodia was particularly obvious in dendrites $(a)$. Scale bar in $a, 20 \mu \mathrm{m}$. 


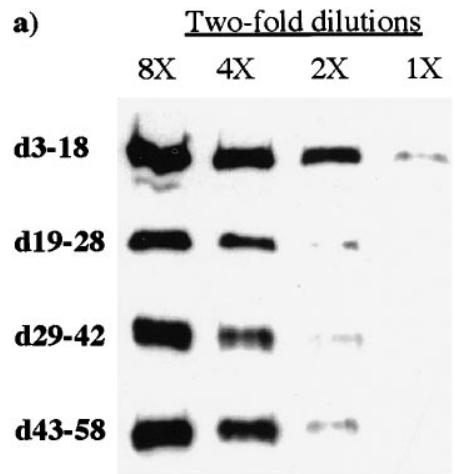

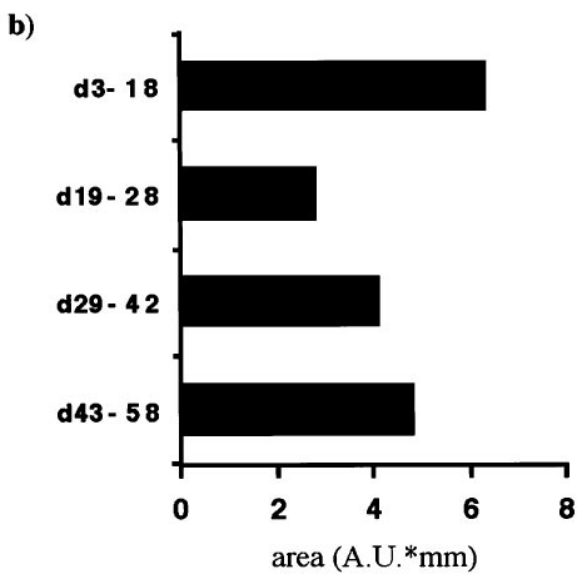

Figure 3. Western blot analysis of the levels of expression for the four deletion mutants of hTfR spanning amino acids $3-58$. One plate of cortical neurons $(\sim 1.5 \times$ $10^{6}$ cells) was infected for each construct with equal amounts of virus (see Materials and Methods for titers). After $24 \mathrm{hr}$ the cells were homogenized, and equal amounts of protein were analyzed by Western blotting. Four twofold dilutions were loaded for each sample. The lowest dilution is on the left. A fluorogram with signals in the linear range of the film was scanned on a densitometer to quantify the levels of expression. $a$, The film of the twofold dilutions for each construct. $b$, Results of the densitometer quantification. All four constructs showed approximately equal levels of expression, although $d 3-18$ was expressed at slightly higher levels than the others. All four dilutions were visible for $d 3-18$ in the fluorogram, whereas only three were visible for the other constructs. Quantified, $d 3-18$ was expressed at only approximately threefold greater levels than $d 19-28$ and at only $\sim 1.5-$ fold above $d 29-42$ or $d 43-58$. derived indirectly from different expression levels of the four deletion constructs, we compared protein expression in dense cultures of cortical neurons infected with each of the four cytoplasmic domain deletions of the hTfR. One dish of cortical neurons cultured for $14 \mathrm{~d}$ was infected with an equal amount of virus for each of the four mutant hTfR vectors (d3-18, d19-28, d29-42, and d43-58) and then homogenized 24 hr later. Membranes were prepared from the homogenate, and equal protein for each homogenate was loaded in four twofold dilutions for SDS-PAGE and Western analysis. The fluorogram of the samples is shown in Figure $3 a$. Similar band intensities were seen for all four constructs, although d3-18 was expressed at slightly higher levels than the other three (bands are visible for all four of the dilutions of this construct, whereas only the first three dilutions are visible for the others). When quantified by densitometry, there was no more than a threefold difference in expression level between the constructs (Fig. 3b), and that difference occurred between d3-18 (at the high end) and d19-28 (at the low end), yet both of these deletions were targeted to axons as well as dendrites. There was only a 1.5 -fold difference between the expression levels of $\mathrm{d} 3-18$ and the two mutants that show wild-type dendritic targeting (d29-42 and d43-58). Because aberrant axonal localization of the mutant proteins did not correlate with level of expression, the nonpolarized targeting of the N-terminal mutants was not an effect of overexpression.

\section{Deletions $\mathrm{N}$-terminal to the consensus internalization motif affect both dendritic targeting and endocytosis}

The minimal endocytosis motif YTRF beginning at amino acid 20 of the TfR has been proposed to be all that is necessary and sufficient for rapid internalization of the receptor in fibroblasts (Collawn et al., 1990, 1993; Jing et al., 1990). However, other studies have reported effects on endocytosis from more $\mathrm{N}$-terminal mutations, and it has been proposed that the strength of the endocytosis signal can be modified by amino acids spanning the range 7-28 (Girones et al., 1991; McGraw et al., 1991). Because we saw effects on both endocytosis and dendritic targeting with the deletion from amino acids 3-18, outside the YTRF region, we examined further which part of this region might play a role in either of the two sorting events and whether any part of this region might affect only one of these processes.

We divided the 16 amino acid stretch from 3-18 into four deletions of four amino acids each (d3-6, d7-10, d11-14, and d15-18). Figure 4 shows the results of infecting neurons with these vectors. The hTfRs missing either amino acids $3-6$ or 15-18 showed no change from wild type in either intracellular staining or dendritic targeting (Fig. $4 a, b, g, h$ ). These two constructs were found in intracellular puncta restricted to the dendrites. Deletion of amino acids $7-10$ or 11-14, however, resulted both in increased appearance of staining on the plasma membrane and also in localization to axons as well as dendrites (Fig. $4 c-f$ ). Highmagnification images of immunostained processes in Figure 5 demonstrate that the intensity of plasma membrane fluorescence for $\mathrm{d} 7-10$ and $\mathrm{d} 11-14$, which retain the YTRF rapid endocytosis motif (Fig. 5b,c), is similar to that of d19-28 (Fig. 5a), in which the YTRF motif was eliminated. Notice in Figure $5 a-c$ that the staining outlines the surface of the entire process and is not punctate. A pattern of "railroad tracks" is seen with brighter staining along the two edges of the process rather than in the middle, as is characteristic of the staining pattern for plasma membrane proteins in the axon. A high-magnification image of the wild-type hTfR, which is found primarily in intracellular puncta, is shown for comparison in Figure $5 d$. It is striking that every deletion that affected the dendritic localization of hTfR also increased the level of plasma membrane staining, suggesting that dendritic targeting and endocytosis are mediated by overlapping signals and potentially by similar mechanisms.

\section{Recycling endosomes in neurons}

The transferrin receptor has been shown in fibroblasts and epithelial cells to pass through a number of endosomal subcompartments as it recycles to the cell surface (Gruenberg and Maxfield, 1995). After internalization, the receptor is found first in a peripheral compartment termed the sorting endosome; subsequently, it accumulates in a para-Golgi tubular network (Yamashiro et al., 1984) called the recycling endosome. The recycling endosome is proposed to play a role in the polarized sorting of membrane proteins in non-neuronal cells (Mayor et al., 1993; Apodaca et al., 1994; Hopkins et al., 1994; Odorizzi et al., 1996). Because the subcompartments of the endosomal system of neurons have not been characterized extensively, we examined the compartments traversed by the TfR after internalization from the dendritic plasma membrane to identify a recycling endosome that might be used for the polarized sorting of the TfR.

To determine whether neurons have an endosomal compartment with some of the characteristics of the recycling endosome, we followed the pathway of endocytosed fluorescent transferrin (Tf). Figure 6, $a$ and $b$, shows two neurons labeled with Cy3conjugated $\mathrm{Tf}$ that either was added to the culture medium for 20 min before fixation (Fig. $6 a$ ) or was added for $20 \mathrm{~min}$ and then 

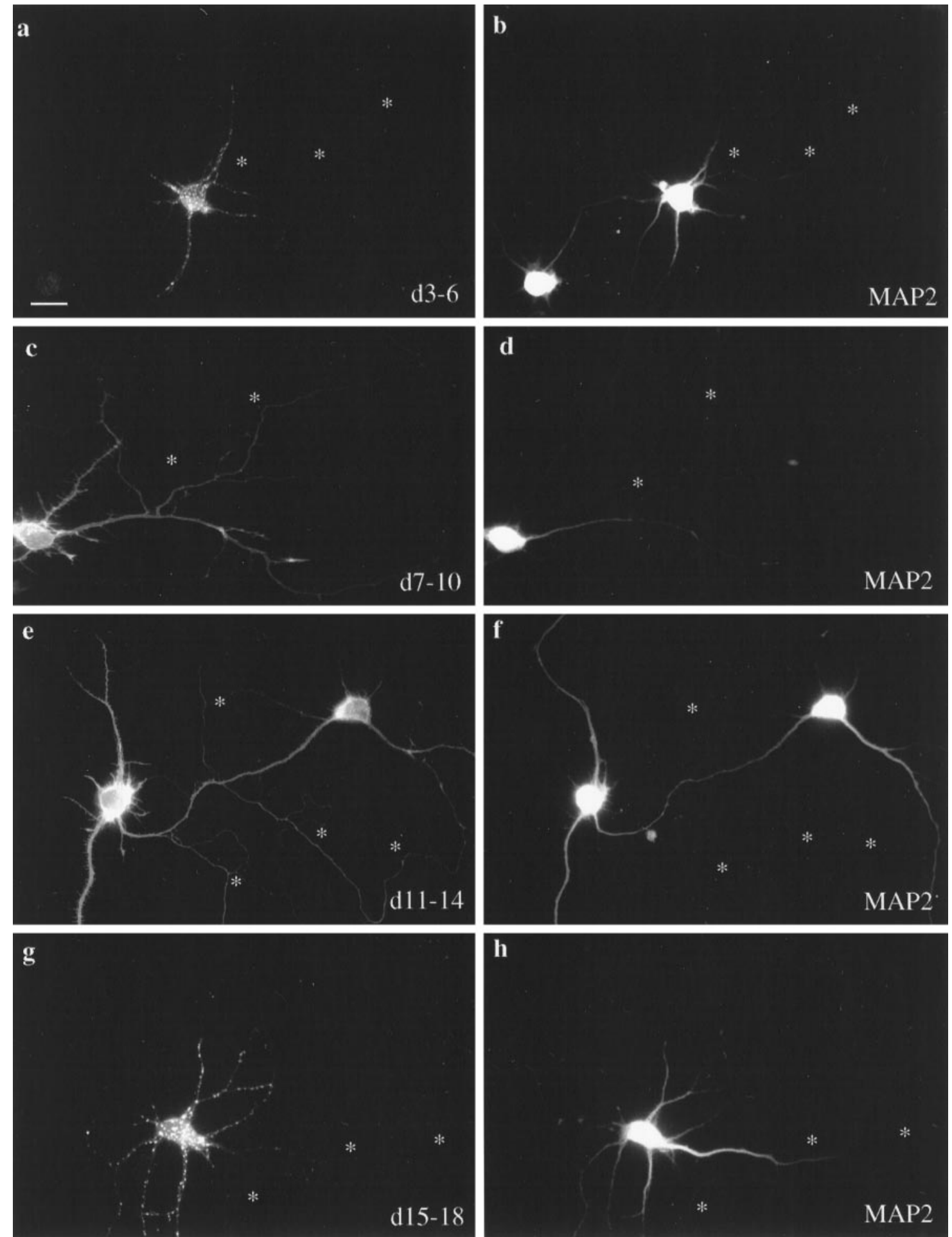

h

Figure 4. Localization of hTfRs containing a four amino acid deletion in the region 3-18. Deletion mutants of hTfR were built by PCR to contain one of the following four amino acid deletions: $d 3-6, d 7-10, d 11-14$, and $d 15-18$. Constructs were expressed in 5-7 DIV cultured hippocampal neurons and localized by immunofluorescence $20 \mathrm{hr}$ later. Dendrites are indicated by $M A P 2$ in $b, d, f$, and $g$. Axons are marked with asterisks. a, d3-6/hTfR; $c$, $d 7-10 / \mathrm{hTfR} ; e, d 11-14 / \mathrm{hTfR} ; g, d 15-18 / \mathrm{hTfR}$. Deletions of amino acids 3-6 or 15-18 had no effect on the dendritic localization or internalization of the transferrin receptor. Deletions from 7-10 or 11-14 caused the constructs to appear in axons as well as dendrites, and the protein was easily detectable on the plasma membrane (note the prominent filopodial staining associated with dendrites in $c$ and $e$ ). Scale bar in $a, 20 \mu \mathrm{m}$.

removed for the $10 \mathrm{~min}$ before fixation (Fig. $6 b$ ). After $20 \mathrm{~min}$ of labeling, bright intracellular staining was seen all along the dendrites and through the cell body. No label was seen in the axon, consistent with the exclusion of the transferrin receptor from the axon. Receptor-mediated endocytosis was assessed by viewing fluorescent $\mathrm{Tf}$ uptake in the presence of a 10-fold molar excess of unlabeled transferrin. No labeling was seen under these conditions (data not shown). 

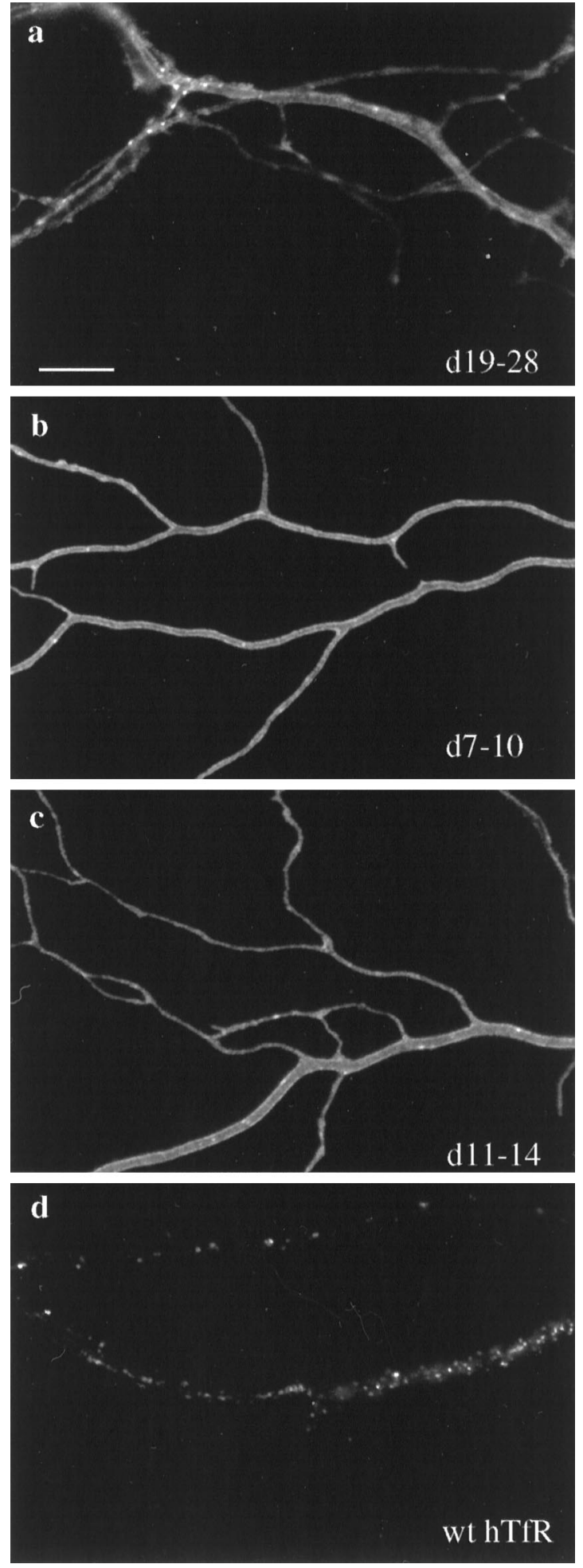

Figure 5. Plasma membrane staining for hTfR deletion mutants 19-28, 7-10, and 11-14. Neurons 5-7 DIV were infected with deletion mutants of hTfR and fixed $20 \mathrm{hr}$ later for immunostaining with OKT9 antibody against hTfR. Cells were photographed at $63 \times$, and the prints were enlarged to demonstrate staining of the plasma membrane. $a, d 19-28 ; b$, $d 7-10 ; c, d 11-14 ; d$, wild-type hTfR (wthTfR). All three mutant constructs showed a similar pattern of immunofluorescence with some intracellular puncta, but the majority of the staining was present on the surface of the processes. The punctate pattern of the wild-type protein is included in $d$ for comparison. Scale bar in $a, 5 \mu \mathrm{m}$.
After a 10 min chase, a large bright region of fluorescent transferrin accumulation was seen in the cell body off to one side of the nucleus (Fig. $6 b$ ) in a position similar to the usual location of the Golgi apparatus. When we compared this transferrin accumulation with the distribution of the TGN as labeled by uptake of C6-NBD-ceramide (Lipsky and Pagan, 1985), we found that, although the ceramide in the TGN (Fig. $6 c$ ) overlapped the transferrin accumulation (Fig. 6b), the markers were in two distinct organelles. The brightest fluorescence for the TGN was near the lower edge of the cell, whereas the most intense accumulations of Tf were near the upper edge. This "para-Golgi" localization of the late part of the TfR endocytic pathway is also characteristic of the recycling endosome in fibroblasts (Connolly et al., 1994). To enhance further the labeling of this compartment and to show that this cell body endosome is distinct from the early sorting endosome, we labeled neurons with fluoresceinconjugated Tf for $60 \mathrm{~min}$, chased for $10 \mathrm{~min}$, and then added DiI-labeled LDL for $5 \mathrm{~min}$. The LDL should be endocytosed by the LDL receptor into early sorting endosomes, marking this first step in the endocytic pathway, whereas the Tf should accumulate in the later part of the recycling pathway. As shown in Figure 6, $d$ and $e$, the endosomes labeled by uptake of DiI-LDL were distinct from the cell body compartment that accumulated Tf. In fact, the patterns of fluorescence for the two compounds are complementary.

Together, these data indicate that endocytosed $\mathrm{Tf}$ accumulates in an organelle with the kinetic features and characteristic intracellular localization of the recycling endosome. This finding is important because recycling endosomes have been shown to be involved in polarized protein sorting in other cell types. Poised at the junction of dendrites and axon in the cell body, this organelle is well positioned to play a regulatory role in the polarized recycling of membrane proteins in neurons.

\section{DISCUSSION}

Our results show that dendritic targeting of the TfR in neurons is mediated by short cytoplasmic sequences. In addition, our results suggest that dendritic targeting and endocytosis of the TfR rely on colinear signals, because every deletion that disturbed dendritic localization also increased the amount of the TfR on the plasma membrane. Finally, we have described somatodendritic recycling endosomes from which polarized protein targeting could occur. Together, these data provide the first molecular analysis of the signals and pathways mediating polarized sorting of a somatodendritic protein in neurons.

\section{A dendritic targeting signal}

We have localized the dendritic targeting signal in TfR to the region of cytoplasmic amino acids $7-28$. Deletion of amino acids $7-10,11-14$, or $19-28$ resulted in a loss of polarized sorting of the mutant TfR constructs. Other deletions of similar size in the cytoplasmic domain did not disturb polarized targeting, indicating that alterations in sorting are unlikely to be attributable to indirect effects of the deletions on the global protein structure. Deletion of the extracellular domain of the transferrin receptor had no effect on targeting (data not shown).

In neurons, removal of the dendritic targeting signal from the $\mathrm{TfR}$ resulted in a nonpolarized distribution, with similar levels of immunofluorescence in axons and dendrites. Similarly, in MadinDarby canine kidney (MDCK) cells in which TfR normally is sorted to the basolateral surface, deletion of the TfR cytoplasmic domain results in equal distributions of the protein on apical and 

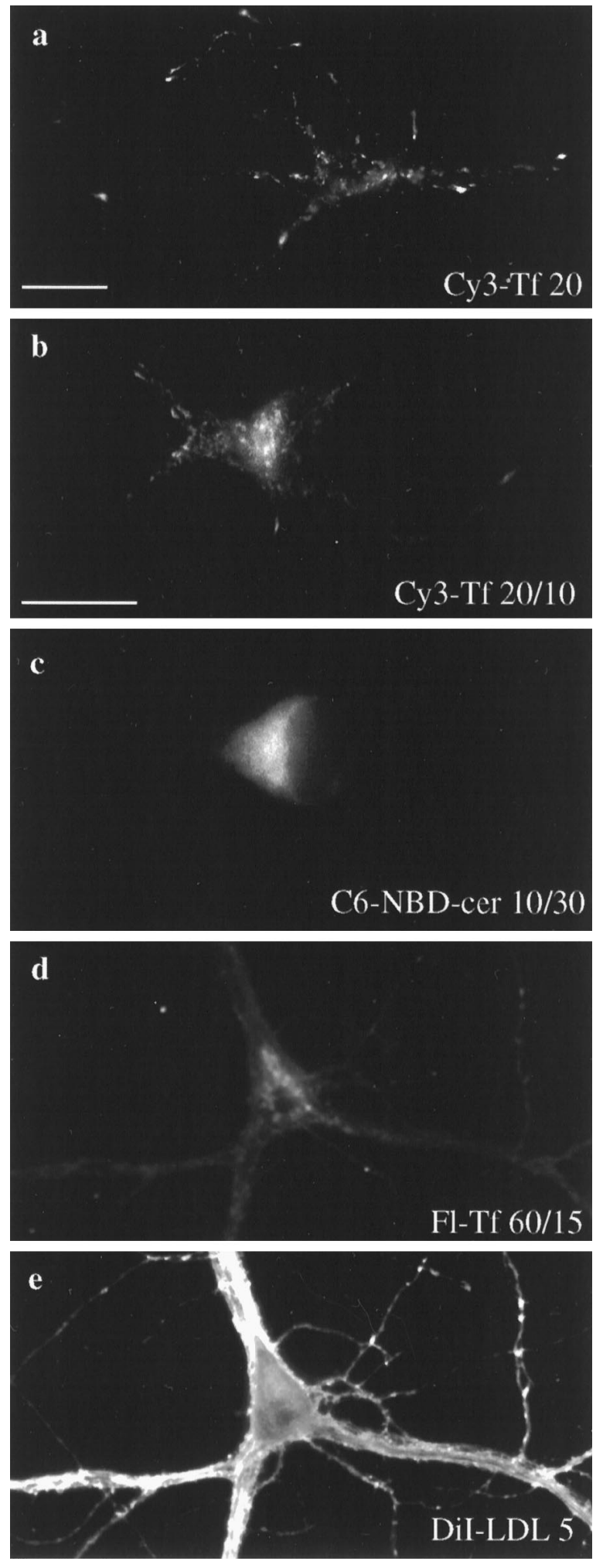

Figure 6. Recycling endosomes in neurons labeled by uptake of fluorescent Tf. Coverslips of neurons at 9-13 DIV were placed face up in 12-well dishes and washed twice with prewarmed HEPES-buffered solution. $a$, The cells were fed $25 \mu \mathrm{g} / \mathrm{ml} \mathrm{Cy3-Tf}$ for $20 \mathrm{~min}$ at $37^{\circ} \mathrm{C}$ in $\mathrm{HEPES}$ buffered solution. $b, c$, C6-NBD-ceramide $(5 \mu \mathrm{M})$ bound to BSA was added to the medium for $10 \mathrm{~min}$. Cy3-Tf at $25 \mu \mathrm{g} / \mathrm{ml}$ was included in the first two $10 \mathrm{~min}$ washes and then removed for $10 \mathrm{~min}$ in the final wash. $d$, $e$, Fluorescein-conjugated $\mathrm{Tf}$ was added to the medium for $60 \mathrm{~min}$ and removed for $10 \mathrm{~min}$, and then DiI-LDL was added to the medium for 5 min. All cells were washed twice with ice-cold HEPES-buffered solution basolateral surfaces (Kundu and Nyak, 1994; Odorizzi et al., 1996). This nonpolarized distribution in epithelial cells is thought to arise from signal-independent delivery, because it matches the bulk flow of vesicular traffic.

These findings build on the observation that short cytoplasmic signals control transmembrane protein targeting to different intracellular destinations in many cell types. KKXX motifs mediate retrieval of resident ER proteins from the Golgi (Jackson et al., 1990). Tyrosine-based signals direct targeting to endosomes, lysosomes, the basolateral domain of epithelial cells, and the TGN (Sandoval and Bakke, 1994; Thomas and Roth, 1994). Di-leucine motifs are similarly multifunctional, directing proteins to endosomes and specialized postendosomal organelles such as lysosomes (Hunziker and Geuze, 1996), the MHC class II complex organelles (Jackson et al., 1995), and synaptic-like microvesicles (Grote et al., 1995).

In this study we have shown that every deletion that disturbed dendritic targeting of the $\mathrm{TfR}$ also increased its appearance on the plasma membrane, suggesting that dendritic targeting and endocytosis of this receptor in neurons rely on the same or very similar signals. This observation contrasts with previous work reporting that basolateral targeting and endocytosis of the TfR in MDCK cells are not mediated by colinear signals (Dargemont et al., 1993). In that study of MDCK type I cells, deletion of amino acids $6-40$ in hTfR rerouted only $20 \%$ of the protein to the apical surface, far less than the $50 \%$ apical hTfR reported for the tailless (d3-59) receptor in MDCK type II cells (Odorizzi et al., 1996). However, type I and II cells differ in their apical/basolateral ratio of plasma membrane (van Bonsdorff et al., 1985; Fuller and Simons, 1986); MDCK I has an apical/basolateral ratio of 1:7.6, whereas MDCK II has a ratio of 1:4. If the deleted TfR follows the flow of bulk membrane and this flow varies according to the apical-to-basolateral membrane ratio, then possibly the truncated TfR was no longer polarized in either case.

The overlap between sequences required for dendritic targeting and endocytosis suggests that signal-dependent mechanisms drive both sorting events. Alternatively, missorting of the mutant receptor to the axon could be a direct result of decreased endocytosis if increased residence time of the receptor in the dendritic plasma membrane allows the protein to diffuse into the axonal plasma membrane. However, an analysis of the kinetics of protein diff usion makes this explanation unlikely. The microscopic diffusion coefficient of transferrin receptor ranges from $10^{-9}$ to $10^{-10}$ $\mathrm{cm}^{2} / \mathrm{sec}$ in different cell types (Sako and Kusumi, 1994). $10^{-9}$ $\mathrm{cm}^{2} / \mathrm{sec}$ is the largest diff usion coefficient reported for transmembrane proteins in biological membranes (Poo and Cone, 1974;

\section{$\leftarrow$}

before fixing. The numbers on the pictures indicate the time of label/ chase. $a$, Twenty minutes; Tf uptake. Bright puncta and tubules were seen throughout the cell body and to the very tips of the dendrites. $b$, Twenty minutes; Tf uptake with a 10 min chase. The total label was less than in $a$, indicating that some TfR had recycled to the surface. A bright accumulation of Tf near the upper part of the left border of the nucleus was visible. Some label remained in the dendrites. $c$, C6-NBD-ceramide label of the TGN. Bright labeling was visible along the left side of the nucleus, but the brightest label was concentrated near the lower border of the cell, distinct from the brightest regions labeled by Tf in $b . d$, Sixty minutes; Tf labeling with a $15 \mathrm{~min}$ chase. The accumulation of Tf next to the nucleus in the cell body was enhanced. $e$, Five minute pulse of DiI-LDL. The brightest staining was located on the edges of the peripheral dendrites. Little staining was visible in the cell body. In this focal plane the patterns of labeling in $d$ and $e$ were essentially complementary. Scale bars: in $a, 20$ $\mu \mathrm{m}$ for $a, d$, and $e$; in $b, 20 \mu \mathrm{m}$ for $b$ and $c$. 
Futerman et al., 1993; Sako and Kusumi, 1994, 1995). However, the rate of diffusion over long distances is at least one to two orders of magnitude smaller, in part because of "fences" or "corrals" that inhibit free diffusion of integral membrane proteins on a micrometer scale (Jacobson et al., 1987; Sako and Kusumi, 1995). We first saw expression of our mutant TfRs $\sim 10 \mathrm{hr}$ after infection and can detect the protein $>100 \mu \mathrm{m}$ into the axon $10 \mathrm{hr}$ later on fixation of the cells (e.g., Figs. $2 a, 4 e$ ). However, given the numbers above, a protein would diffuse only $15 \mu \mathrm{m}$ in $10 \mathrm{hr}$ with the reported macroscopic diffusion constant for TfR of $3.2 \times$ $10^{-11} \mathrm{~cm}^{2} / \mathrm{sec}$ (Futerman et al., 1993; Sako and Kusumi, 1994).

\section{Coated vesicle-mediated protein sorting}

Coat proteins such as clathrin facilitate intracellular membrane traffic by providing the necessary energy to deform the donor membrane into transport vesicles that travel to the target organelle. In addition to this mechanical function, coat-associated proteins (or "adaptors") such as the clathrin vesicle proteins AP1 and AP2 influence the contents of these transport vesicles by interacting selectively with the cytoplasmic domains of proteins in the donor membrane (Marks et al., 1997; Robinson, 1997). In this manner, adaptor proteins may act as recognition factors for intracellular sorting signals (Heilker et al., 1996).

The overlap between the dendritic targeting signal in TfR and the rapid endocytosis motif implies that recognition of this region by clathrin-associated coat proteins may be the mechanism that drives both of these sorting events-to the endosome from the dendritic plasma membrane and to the dendritic plasma membrane from the recycling endosome. A similar overlap with a tyrosine-based rapid endocytosis motif has been observed for signals that target transmembrane proteins to lysosomes (Hunziker and Geuze, 1996) and to the basolateral surface of polarized epithelial cells (Matter and Mellman, 1994). Many novel adaptor-like coat proteins now have been identified that may provide a mechanism for the specificity of adaptor/sorting signal recognition, based on the different avidities of these adaptor proteins for each sorting signal (Marks et al., 1997).

Sorting of the TfR in neurons could be mediated by interaction with coated vesicle-associated proteins at several points. Clathrincoated vesicles forming from the TGN contain the AP1 adaptor complex (Pearse and Robinson, 1990), which is recruited to the TGN membrane by binding to the sequence ESEER in the cytoplasmic domain of the mannose 6-phosphate receptor (Mauxion et al., 1996). An "acid patch" sequence similar to this one modulates the activity of the basolateral sorting signals in the LDL receptor (Matter et al., 1992); however, deletion of the only similar sequence in hTfR (DEEE at amino acids 43-46) did not affect dendritic targeting in this study. The AP2 adaptor complex is found on clathrin-coated vesicles derived from the plasma membrane, and interaction of the $\mu$-chain of this complex with the rapid endocytosis motif of TfR is thought to target TfR from the plasma membrane to endosomes (Ohno et al., 1995). Endosomes in fibroblasts have clathrin-coated buds that contain a novel AP complex (Stoorvogel et al., 1996). Neurons also contain another newly identified AP complex, which contains the proteins $\beta$-NAP and 447 , localizes to both the TGN and to endosomes, and could be involved with the recognition of sorting signals from either of these compartments (Simpson et al., 1996).

\section{Dendritic retrieval from the recycling endosome}

In neurons we have shown that transferrin internalized into the dendrites accumulates in a compartment with the characteristics of a recycling endosome. In contrast to the sorting endosome, the recycling endosome is poorly labeled by fluid phase markers, but it is accessible to recycling membrane proteins from either the apical or basolateral surface (Apodaca et al., 1994; Odorizzi et al., 1996). The neuronal recycling endosome is located at the junction of axons and dendrites, where it could regulate the transport of proteins into these two types of processes. Even if targeted directly to a polarized surface from the TGN, recycling transmembrane proteins must be resorted with each round of internalization. The steady-state polarized distribution of a recycling transmembrane protein like the TfR therefore must depend on repeated recognition of the somatodendritic sorting signals in the recycling endosome and targeted retrieval to the dendritic plasma membrane. Because there are transcytotic pathways along which membrane and membrane proteins travel from the dendrites to the axon (de Hoop et al., 1995), proper dendritic retrieval of transferrin receptor requires recognition of the dendritic targeting signal in this central recycling endosome to prevent entry into the axon. Recognition of the central role of this endosomal subcompartment in the polarized recycling of transmembrane proteins should help focus future efforts to identify the proteins that recognize the somatodendritic targeting signals on transferrin receptor and other dendritic transmembrane proteins.

\section{REFERENCES}

Ali SA, Steinkasserer A (1995) PCR ligation-PCR mutagenesis: a protocol for creating gene fusions and mutations. Biotechniques 18:746-749.

Apodaca G, Katz LA, Mostov KE (1994) Receptor-mediated transcytosis of IgA in MDCK cells via apical recycling endosomes. J Cell Biol 125:67-86.

Banker GA, Cowan WM (1977) Rat hippocampal neurons in dispersed cell culture. Brain Res 126:397-425.

Caceres A, Banker G, Steward O, Binder L, Payne M (1984) MAP2 is localized to the dendrites of hippocampal neurons which develop in culture. Dev Brain Res 13:314-318.

Cameron PL, Südhof TC, Jahn R, De Camilli P (1991) Colocalization of synaptophysin with transferrin receptors: implications for synaptic vesicle biogenesis. J Cell Biol 115:151-164.

Collawn JF, Stangel M, Kuhn LA, Esekogwu V, Jing SQ, Trowbridge IS, Tainer JA (1990) Transferrin receptor internalization sequence YXRF implicates a tight turn as the structural recognition motif for endocytosis. Cell 63:1061-1072.

Collawn JF, Lai A, Domingo D, Fitch M, Hatton S, Trowbridge IS (1993) YTRF is the conserved internalization signal of the transferrin receptor, and a second YTRF signal at position 31-34 enhances endocytosis. J Biol Chem 268:21686-21692.

Connolly CN, Futter CE, Gibson A, Hopkins CR, Cutler DF (1994) Transport into and out of the Golgi complex studied by transfecting cells with cDNAs encoding horseradish peroxidase. J Cell Biol 127:641-652.

Craig AM, Banker G (1994) Neuronal polarity. Annu Rev Neurosci 17:267-310.

Dargemont C, Le Bivic A, Rothenberger S, Iacopetta B, Kühn LC (1993) The internalization signal and the phosphorylation site of transferrin receptor are distinct from the main basolateral sorting information. EMBO J 12:1713-1721.

Dautry-Versat A, Ciechanover A, Lodish HF (1983) pH and the recycling of transferrin during receptor-mediated endocytosis. Proc Natl Acad Sci USA 80:2258-2262.

de Hoop MJ, von Poser C, Lange C, Ikonen E, Hunziker W, Dotti CG (1995) Intracellular routing of wild-type and mutated polymeric immunoglobulin receptor in hippocampal neurons in culture. J Cell Biol 130:1447-1459.

Dotti CG, Sullivan CA, Banker GA (1988) The establishment of polarity by hippocampal neurons in culture. J Neurosci 8:1454-1468.

Fletcher TL, Cameron P, De Camilli P, Banker G (1991) The distribution of synapsin I and synaptophysin in hippocampal neurons developing in culture. J Neurosci 11:1617-1626.

Fuller SD, Simons K (1986) Transferrin receptor polarity and recycling 
accuracy in "tight" and "leaky" strains of Madin-Darby canine kidney cells. J Cell Biol 103:1767-1779.

Futerman AH, Khanin R, Segal LA (1993) Lipid diffusion in neurons. Nature 362:119.

Geller AI, Breakefield XO (1988) A defective HSV-1 vector expresses Escherichia coli beta-galactosidase in cultured peripheral neurons. Science 241:1667-1669.

Geller AI, During MJ, Neve RL (1991) Molecular analysis of neuronal physiology by gene transfer into neurons with herpes simplex virus vectors. Trends Neurosci 14:428-432.

Geller AI, During MJ, Haycock JW, Freese A, Neve R (1993) Longterm increases in neurotransmitter release from neuronal cells expressing a constitutively active adenylate cyclase from a herpes simplex virus type 1 vector. Proc Natl Acad Sci USA 90:7603-7607.

Girones N, Alverez E, Seth A, Lin IM, Latour DA, Davis RJ (1991) Mutational analysis of the cytoplasmic tail of the human transferrin receptor. Identification of a subdomain that is required for rapid endocytosis. J Biol Chem 266:19006-19012.

Goldstein JL, Brown MS, Anderson RGW, Russell DW, Schneider WJ (1985) Receptor-mediated endocytosis: concepts emerging from the LDL receptor system. Annu Rev Cell Biol 1:1-39.

Goslin K, Banker G (1991) Rat hippocampal neurons in low density culture. In: Culturing nerve cells (Banker G, Goslin K, eds), pp 251282. Cambridge, MA: MIT.

Grote E, Hao JC, Bennett MK, Kelly RB (1995) A targeting signal in VAMP regulating transport to synaptic vesicles. Cell 81:581-589.

Gruenberg J, Maxfield FR (1995) Membrane transport in the endocytic pathway. Curr Opin Cell Biol 7:552-563.

Heilker R, Manning-Kreig U, Zuber J-F, Spiess M (1996) In vitro binding of clathrin adaptors to sorting signals correlates with endocytosis and basolateral sorting. EMBO J 15:2893-2899.

Ho DY (1994) Amplicon-based herpes simplex viral vectors. Methods Cell Biol 43:191-210.

Hopkins CR, Gibson A, Shipman M, Strickland DK, Trowbridge IS (1994) In migrating fibroblasts, recycling receptors are concentrated in narrow tubules of the pericentriolar area and then routed to the plasma membrane of the leading lamella. J Cell Biol 125:1265-1274.

Hunziker W, Geuze HJ (1996) Intracellular trafficking of lysosomal membrane proteins. Bioessays 18:379-389.

Jackson MR, Nilsson T, Peterson PA (1990) Identification of a consensus motif for retention of transmembrane proteins in the endoplasmic reticulum. EMBO J 9:3153-3162.

Jackson MR, Früh K, Karlsson L, Teyton L, Yang Y, Peterson PA (1995) Assembly and intracellular transport of MHC class I and class II molecules. Cold Spring Harb Symp Quant Biol 60:249-261.

Jacobson K, Ishihara A, Inman R (1987) Lateral diff usion of proteins in membranes. Annu Rev Physiol 49:163-175.

Jing SQ, Spencer T, Miller K, Hopkins C, Trowbridge IS (1990) Role of the human transferrin receptor cytoplasmic domain in endocytosis: localization of a specific signal sequence for internalization. J Cell Biol 110:283-294.

Knight A, Hughson E, Hopkins CR, Cutler DF (1995) Membrane protein trafficking through the common apical endosome in Caco-2 cells. Mol Biol Cell 6:597-610.

Kundu A, Nayak DP (1994) Analysis of the signals for polarized transport of influenza virus (A/WSN/33) neuraminidase and human transferrin receptor, type II transmembrane proteins. J Virol 68:1812-1818.

Lim F, Hartley D, Starr P, Lang P, Song S, Yu L, Wang Y, Geller AI (1996) Generation of high-titer defective HSV-1 vectors using an IE 2 deletion mutant and quantitative study of expression in cultured cortical cells. Biotechniques 20:460-469.

Lipsky NG, Pagan RE (1985) A vital stain for the Golgi apparatus. Science 228:745-757.

Marks MS, Ohno H, Kirchhausen T, Bonifacino JS (1997) Protein sorting by tyrosine-based signals: adapting to the Ys and wherefores. Trends Cell Biol 7:124-128.

Matter K, Mellman I (1994) Mechanisms of cell polarity: sorting and transport in epithelial cells. Curr Opin Cell Biol 6:545-554.

Matter K, Hunziker W, Mellman I (1992) Basolateral sorting of LDL receptor in MDCK cells: the cytoplasmic domain contains two tyrosine-dependent targeting determinants. Cell 71:741-753.

Matter K, Whitney JA, Yamamoto EM, Mellman I (1993) Common signals control low-density lipoprotein receptor sorting in endosomes and the Golgi complex of MDCK cells. Cell 74:1053-1064.
Mauxion F, Leborgne R, Munierlehmann H, Hoflack B (1996) A casein kinase site in the cytoplasmic domain of the cation-dependent mannose 6-phosphate receptors determines the high-affinity interaction of the AP-1 Golgi assembly proteins with membranes. J Biol Chem 271:2171-2178

Mayor S, Presley JF, Maxfield FR (1993) Sorting of membrane components from endosomes and subsequent recycling to the cell surface occurs by a bulk flow process. J Cell Biol 121:1257-1269.

McCarthy AM, McMahan L, Schaffer PA (1989) Herpes simplex virus type I ICP27 deletion mutants exhibit altered patterns of transcription and are DNA deficient. J Virol 63:18-27.

McClelland A, Kühn LC, Ruddle FH (1984) The human transferrin receptor gene: genomic organization and the complete primary structure of the receptor deduced from a cDNA sequence. Cell 39:267-274.

McGraw TE, Pytowski B, Arzt J, Ferrone C (1991) Mutagenesis of the human transferrin receptor: two cytoplasmic phenylalanines are required for efficient internalization, and a second-site mutation is capable of reverting an internalization-defective phenotype. J Cell Biol 112:853-861.

Odorizzi G, Pearse A, Domingo D, Trowbridge IS, Hopkins CR (1996) Apical and basolateral endosomes of MDCK cells are interconnected and contain a polarized sorting mechanism. J Cell Biol 135:139-152.

Ohno H, Stewart J, Fournier M-C, Bosshart H, Rhee I, Miyatake S, Saito T, Gallusser A, Kirchhausen T, Bonifacino JS (1995) Interaction of tyrosine-based sorting signals with clathrin-associated proteins. Science 269:1872-1875.

Olkkonen VM, Liljestroem P, Dupree P, Garoff H, Simons K (1994) Expression of exogenous proteins in mammalian cells with the Simliki Forest virus vector. Methods Cell Biol 43:43-53.

Parton RG, Simons K, Dotti CG (1992) Axonal and dendritic endocytic pathways in cultured neurons. J Cell Biol 119:123-137.

Pearse BMF, Robinson MS (1990) Clathrin, adaptors, and sorting. Annu Rev Cell Biol 6:151-171.

Poo M-M, Cone RA (1974) Lateral diffusion of rhodopsin in the photoreceptor membrane. Nature 247:438-441.

Robinson MS (1997) Coats and vesicle budding. Trends Cell Biol 7:99-102.

Sako Y, Kusumi A (1994) Compartmentalized structure of the plasma membrane as revealed by nanometer-level motion analysis. J Cell Biol 125:1251-1264.

Sako Y, Kusumi A (1995) Barriers for lateral diffusion of transferrin receptor in the plasma membrane as characterized by receptor dragging by laser tweezers: fence versus tether. J Cell Biol 129:1559-1574.

Sandoval IV, Bakke O (1994) Targeting of membrane proteins to endosomes and lysosomes. Trends Cell Biol 4:292-297.

Simpson F, Bright NA, West MA, Newman LS, Darnell RB, Robinson MS (1996) A novel adaptor-related protein complex. J Cell Biol 133:749-760.

Smith IL, Hardwicke MA, Sandri-Goldin RM (1992) Evidence that the herpes simplex virus immediate early protein ICP27 acts posttranscriptionally during infection to regulate gene expression. Virology 186:74-86.

Spaete RR, Frenkel N (1982) The herpes simplex virus amplicon: a new eukaryotic defective-virus cloning-amplifying vector. Cell 30:295-304.

Stoorvogel DR, Oorshot V, Geuze HJ (1996) A novel class of clathrincoated vesicles budding from endosomes. J Cell Biol 132:21-33.

Sutherland DR, Delia D, Schneider C, Newman RA, Kemshead J, Greaves MF (1981) Ubiquitous cell-surface glycoprotein on tumor cells is a proliferation-associated receptor for transferrin. Proc Natl Acad Sci USA 78:4515-4519.

Thomas DC, Roth MG (1994) The basolateral targeting signal in the cytoplasmic domain of glycoprotein $\mathrm{G}$ from vesicular stomatitis virus resembles a variety of intracellular targeting motifs related by primary sequence but having diverse targeting activities. J Biol Chem 269:15732-15739.

van Bonsdorff C-H, Fuller SD, Simons K (1985) Apical and basolateral endocytosis in Madin-Darby canine kidney (MDCK) cells grown on nitrocellulose filters. EMBO J 4:2781-2792.

Yamashiro DL, Tycko B, Fluss SR, Maxfield FR (1984) Segregation of transferrin to a mildly acidic $(\mathrm{pH}$ 6.4) para-Golgi compartment in the recycling pathway. Cell 37:789-800. 